\title{
The ingestion of sow's faeces by suckling piglets
}

\author{
BY B. F. SANSOM AND P. T. GLEED \\ Agricultural Research Council, Institute for Research on Animal Diseases, Compton, \\ Newbury, Berkshire, RG16 ONN
}

(Received 9 April 1981-Accepted 27 May 198I)

\begin{abstract}
1. Six sows were housed in solij-floored farrowing pens and fed daily with approximately $200 \mu \mathrm{Ci}{ }^{198} \mathrm{Au}$, three of them from $3 \mathrm{~d}$ before farrowiag until their piglets were $10 \mathrm{~d}$ old and three from $10 \mathrm{~d}$ after farrowing until their piglets were weaned at $21 \mathrm{~d}$.

2. The sows' faeces and sawdust bedding became radioactive but their milk remained free of radioactivity. The piglets' radioactivity was miasured daily in a whole-body counter after they had been washed to remove external contamination.

3. The piglets' mean whole-body radioactivity was equivalent to $20.9 \pm 2.5 \mathrm{~g}$ (range $5 \cdot 7-85 \mathrm{~g}$ ) of faeces and bedding. If the average passage time of the digesta through the gastrointestinal tract is assumed to be $24 \mathrm{~h}$ these values are equal to the average daily intake of faeces and bedding by the piglets.

4. This intake of faeces cou.d possibly prevent the piglets becoming anaemic if the sow's diet were supplemented with iron to incriase the Fe concentration of her faeces to approximately $2 \mathrm{mg} \mathrm{Fe} / \mathrm{g}$ fresh faeces.
\end{abstract}

Piglets become anaemic if they do not receive supplies of iron other than that in the sow's milk (Braude et al. 1962). Under natural or free-range conditions the piglets can obtain the rest of their requirement for Fe from soil (Venn et al. 1947), but in modern husbandry conditions soil is not availa.ble. However, if the sow farrows in a solid-floored pen, and her faeces contain high concentrations of $\mathrm{Fe}$ the piglets might obtain sufficient $\mathrm{Fe}$ (approximately $7 \mathrm{mg} / \mathrm{d}$ ) from the faeces to avoid becoming anaemic.

Recently a feed additive (Fetal Iron; Albion Laboratories Inc., Clearfield, Utah, USA) has been developed which is claimed to enrich the sow's milk with sufficient Fe to prevent the piglets becoming anaeraic. However, Brady et al. (1978) have shown that feeding sows with $3000 \mathrm{mg} \mathrm{Fe} / \mathrm{kg}$ in this form did not increase the concentration of $\mathrm{Fe}$ in their milk sufficiently to account for the beneficial effect which the sow's diet had on their piglets' haemoglobin concentration. They suggested that this effect must have been due to the ingestion by the piglets of sime of the sow's Fe-rich faeces. In order to estimate the potential value of this source of $\mathrm{Fe}$ for the prevention of piglet anaemia the present experiments were designed to measure directly the intake of sow's faeces by piglets.

The sows received daily oral doses of colloidal ${ }^{198} \mathrm{Au}$, a non-absorbed marker, which labelled their faeces with radioactivity. The amount of radioactivity present in the piglets was measured in a whole-tiody counter (Sansom et al. 1971). A preliminary account of the results has been published (Sansom \& Gleed, 1981).

\section{MATERIALS AND METHODS}

Six Large White ( $x$ Landrace) sows and their litters were used for the experiment. At $3 \mathrm{~d}$ before their estimated farrowing dates the sows were moved into a solid-floored farrowing pen and bedded on approximately $2 \mathrm{~kg}$ wood shavings. This bedding was replaced daily, before the sow was fed, and put into a plastic sack, together with the previous $24 \mathrm{~h}$ output of faeces, for determination of radioactivity. Three of the sows and their litters were used to study the ingestion of faeces by piglets between birth and $10 \mathrm{~d}$ of age and the other three sows and their litters were used to study the ingestion of faeces between 10 and $21 \mathrm{~d}$.

Sows were dosed daily with approximately $200 \mu \mathrm{Ci}{ }^{198} \mathrm{Au}$ (code GCS-IP; The Radio- 
chemical Centre, Amersham, Bucks) stabilized in a gelatin and glucose solution. The dose was absorbed into pig nuts which were offered to the sow just before her morning feed. Care was taken to ensure that no radioactive material was spilt on to the floor. Three sows were dosed from the time they entered the farrowing pen until the piglets were slaughtered at $10 \mathrm{~d}$ old. The other three sows were dosed from $8 \mathrm{~d}$ after farrowing until the piglets were slaughtered at $21 \mathrm{~d}$.

The piglets were washed daily using soap and warm water to remove any external faecal contamination and were dried using clean wood shavings before they were individually counted for $5 \mathrm{~min}$ in a whole-body counter. In the counter the piglets were restrained in a wooden box with Perspex inserts whose position could be adjusted as the piglets grew. The counts were corrected for background radiation and for the decrease in counting efficiency which occurred as the piglets grew. The bedding material and faeces collected each morning were also counted using the same geometry, and similar corrections were applied to the counts obtained. After counting in the whole-body counter the faeces and bedding were thoroughly homogenized and a $1 \mathrm{~g}$ sample counted in an NE8311 gamma-scintillation counter. The results obtained were used to establish the relative counting efficiencies of the gamma-scintillation counter and the whole-body counter, which were approximately 20 and $3 \%$ respectively.

Just before slaughter on either day 10 or 21 a $5 \mathrm{ml}$ blood sample was taken from the anterior vena cava of each piglet and counted in the gamma-scintillation counter. The piglets were slaughtered by electrocution, washed thoroughly and counted in the whole-body counter. The gastrointestinal tract was then removed and the empty carcase re-counted.

Milk samples were taken at intervals from the sows and counted in the gamma-scintillation counter.

They were taken just before the piglets were returned to the sow after whole-body counting, thus allowing approximately $1 \mathrm{~h}$ for the udder to fill. The udder was thoroughly washed to remove faecal contamination and milk flow was induced with an intramuscular injection of $1 \mathrm{ml}$ pituitary extract.

\section{RESULTS}

Table 1 shows the radioactivity measured on each day in the piglets from litter no. 2 . The piglets appear to have ingested as much radioactivity on the first day of their exposure to the radioactive faeces as on the subsequent days, and similar patterns of uptake of

Table 1. Whole body radioactivity (counts/s) in piglets of litter no. 2 during the first $10 \mathrm{~d}$ after birth

\begin{tabular}{|c|c|c|c|c|c|c|c|c|c|}
\hline \multirow{2}{*}{$\begin{array}{l}\text { Age } \\
\text { (d) }\end{array}$} & \multicolumn{9}{|c|}{ Piglet no. } \\
\hline & 1 & 2 & 3 & 4 & 5 & 6 & 7 & 8 & 9 \\
\hline 1 & 324 & 348 & 245 & 145 & 305 & 407 & 377 & 254 & 161 \\
\hline 2 & 441 & 559 & 347 & 230 & 309 & 476 & 430 & 353 & 261 \\
\hline 3 & 367 & 406 & 324 & 180 & 257 & 388 & 408 & 349 & 230 \\
\hline 4 & 302 & 257 & 302 & 129 & 238 & 293 & 349 & 313 & 219 \\
\hline 5 & 299 & 339 & 315 & 212 & 320 & 366 & 404 & 430 & 274 \\
\hline 6 & 224 & 351 & 257 & 175 & 261 & 359 & 398 & 344 & 204 \\
\hline 7 & 249 & 386 & 272 & 187 & 273 & 287 & 376 & 324 & 211 \\
\hline 8 & 219 & 349 & 250 & 206 & 287 & 355 & 269 & 332 & 246 \\
\hline 9 & 253 & 430 & 340 & 269 & 350 & 514 & 480 & 434 & 277 \\
\hline 10 & 306 & 403 & 283 & 251 & 315 & 519 & 464 & 392 & 288 \\
\hline Mean & 298 & 383 & 294 & 198 & 292 & 396 & 395 & 352 & 237 \\
\hline SEM & 22 & 25 & 12 & 14 & 11 & 26 & 19 & 17 & 12 \\
\hline
\end{tabular}


Table 2. Mean whole-bcdy radioactivity (counts/s) of piglets during the first $10 \mathrm{~d}$ after birth (litters nos. 1-3) and from 10-21 d (litters nos. 4-6)

\begin{tabular}{|c|c|c|c|c|c|c|}
\hline \multirow[b]{2}{*}{ Piglet no. } & \multicolumn{3}{|c|}{$\begin{array}{c}\text { Period of measurement } \\
0-10 \mathrm{~d}\end{array}$} & \multicolumn{3}{|c|}{$\begin{array}{l}\text { Period of measurement } \\
11-21 \mathrm{~d}\end{array}$} \\
\hline & $\begin{array}{l}\text { Litter } \\
\text { no. } 1\end{array}$ & $\begin{array}{l}\text { Litter } \\
\text { no. } 2\end{array}$ & $\begin{array}{l}\text { Litter } \\
\text { no. } 3\end{array}$ & $\begin{array}{l}\text { Litter } \\
\text { no. } 4\end{array}$ & $\begin{array}{l}\text { Litter } \\
\text { no. } 5\end{array}$ & $\begin{array}{l}\text { Litter } \\
\text { no. } 6\end{array}$ \\
\hline 1 & 656 & 298 & 126 & 729 & 124 & 223 \\
\hline 2 & 372 & 383 & 148 & 762 & 266 & 257 \\
\hline 3 & 528 & 294 & 118 & 1079 & 248 & 232 \\
\hline 4 & 575 & 198 & 116 & 1359 & 184 & 188 \\
\hline 5 & 644 & 292 & 118 & 1468 & 153 & 187 \\
\hline 6 & 380 & 396 & 188 & 1703 & 180 & 152 \\
\hline 7 & 586 & 395 & 149 & 1348 & 248 & 186 \\
\hline 8 & 185 & 352 & 230 & - & 196 & 157 \\
\hline 9 & 690 & 237 & 188 & - & 266 & 140 \\
\hline 10 & - & - & 263 & - & 330 & - \\
\hline Mean & 513 & 316 & 164 & 1207 & 220 & 191 \\
\hline SEM & 56 & 24 & 16 & 138 & 20 & 13 \\
\hline $\begin{array}{l}\text { Coefficient } \\
\text { of variation }\end{array}$ & 33 & 23 & 31 & 30 & 29 & 20 \\
\hline
\end{tabular}

Mean ( \pm . SE) of litter means $435 \pm 163$, coefficient of variation 92

Table 3. Average weights of faeces and bedding removed daily from the sows' pens and its average radioactive concentration (counts/s per g) during the period when the sows were dosed daily with approximately $200 \mu \mathrm{Ci}{ }^{198} \mathrm{Au}$

\begin{tabular}{ccc}
\hline \hline $\begin{array}{c}\text { Sow } \\
\text { no. }\end{array}$ & $\begin{array}{c}\text { Wt of bedding } \\
\text { and faeces (kg) }\end{array}$ & $\begin{array}{c}\text { Radioactive concentration } \\
\text { (counts/s per g) }\end{array}$ \\
\hline 1 & 7.1 & 19.5 \\
2 & 8.8 & 16.1 \\
3 & 11.3 & 16.2 \\
4 & 7.2 & 19.7 \\
5 & 7.85 & 21.7 \\
6 & 9.1 & 20.6 \\
\hline
\end{tabular}

radioactivity were observed in litters nos. 3-5. However, in litters nos. 1 and 6 a more gradual increase in whole-body radioactivity occurred in the piglets during the first 3-5 d. This different pattern appeared to be related to a temporary period of inappetance in the sow, during which she passed only small quantities of faeces; subsequently the piglets' whole-body radioactivity became approximately constant as in litters nos. 2-5.

For each piglet a mean whole-body radioactivity has been calculated as in Table 1. For litters nos. 2-5 all the vaiues have been used, and for litters nos. 1 and 6 only the values obtained when the sows' appetite and faecal output were normal. These mean values for all the piglets in the six litters are shown in Table 2 . There were wide variations among piglets within litters (e.g. piglets nos. 8 and 9 in litter no. 1 , and piglets nos. 1 and 6 in litter no. 4) and even wider variations among litters (eg. litters nos. 3 and 4).

Table 3 records the average weights of faeces and bedding removed daily from the sows' pens during the experiment and its average radioactive concentration. Table 4 gives the 
Table 4. Mean weight $(\mathrm{g})$ of faeces and bedding material present in piglets during the first $10 \mathrm{~d}$ after birth (litters nos. 1-3) and from 10-21 d (litters nos. 4-6)

\begin{tabular}{|c|c|c|c|c|c|c|}
\hline \multirow[b]{2}{*}{ Piglet no. } & \multicolumn{3}{|c|}{$\begin{array}{l}\text { Period of measurement } \\
0-10 \mathrm{~d}\end{array}$} & \multicolumn{3}{|c|}{$\begin{array}{l}\text { Period of measurement } \\
\qquad 10-21 \mathrm{~d}\end{array}$} \\
\hline & $\begin{array}{l}\text { Litter } \\
\text { no. } 1\end{array}$ & $\begin{array}{l}\text { Litter } \\
\text { no. } 2\end{array}$ & $\begin{array}{l}\text { Litter } \\
\text { no. } 3\end{array}$ & $\begin{array}{l}\text { Litter } \\
\text { no. } 4\end{array}$ & $\begin{array}{l}\text { Litter } \\
\text { no. } 5\end{array}$ & $\begin{array}{l}\text { Litter } \\
\text { no. } 6\end{array}$ \\
\hline 1 & 33.6 & 18.5 & 7.7 & 37.0 & 5.7 & 10.8 \\
\hline 2 & 19.1 & 23.8 & 9.1 & 38.7 & 12.3 & 12.5 \\
\hline 3 & $27 \cdot 1$ & $18 \cdot 3$ & $7 \cdot 3$ & 54.8 & 11.4 & $11 \cdot 3$ \\
\hline 4 & $29 \cdot 5$ & 12.4 & $7 \cdot 2$ & $69 \cdot 0$ & 8.5 & 9.1 \\
\hline 5 & 33.0 & 18.1 & $7 \cdot 3$ & 74.5 & $7 \cdot 1$ & 9.1 \\
\hline 6 & 19.5 & $24 \cdot 6$ & 11.6 & $86 \cdot 4$ & $8 \cdot 3$ & $7 \cdot 4$ \\
\hline 7 & 30.1 & $24 \cdot 5$ & 9.2 & 68.4 & $11 \cdot 4$ & 9.0 \\
\hline 8 & 9.5 & 21.9 & $14 \cdot 2$ & - & 9.0 & 7.6 \\
\hline 9 & $35 \cdot 4$ & 14.7 & 11.6 & - & $12 \cdot 3$ & 6.8 \\
\hline 10 & - & - & $16 \cdot 2$ & - & 15.2 & - \\
\hline Mean & $26 \cdot 3$ & $19 \cdot 6$ & $10 \cdot 1$ & $61 \cdot 2$ & $10 \cdot 1$ & $9 \cdot 3$ \\
\hline SEM & 2.9 & 1.5 & 1.0 & 7.0 & 0.9 & 0.6 \\
\hline
\end{tabular}

Over-all mean ( $\pm \mathrm{SE}) 20.9 \pm 2 \cdot 5$

Table 5. Mean radioactivity (counts/s) of whole piglet carcases before and after removal of gastrointestinal tract (GD)

\begin{tabular}{cccc}
\hline $\begin{array}{c}\text { Litter } \\
\text { no. }\end{array}$ & $\begin{array}{c}\text { Mean radioactivity } \\
\text { in whole carcase } \\
\text { (counts/s) }\end{array}$ & $\begin{array}{c}\text { Mean radioactivity } \\
\text { in whole carcase } \\
\text { after removal of } \\
\text { GI tract (counts/s) }\end{array}$ & $\begin{array}{c}\text { Mean radioactivity } \\
\text { in whole carcase } \\
\text { after removal of } \\
\text { GI tract }(\%)\end{array}$ \\
\hline 1 & 505 & 56 & $11 \cdot 1$ \\
2 & 353 & 34 & 9.6 \\
3 & 404 & 43 & 10.6 \\
4 & 1982 & 111 & 5.6 \\
5 & 433 & 20 & 9.6 \\
6 & 382 & 38 & 9.9 \\
\hline
\end{tabular}

Table 6. Radioactivity (counts/s) present, at slaughter, on the skin of piglet carcases

\begin{tabular}{cccc}
\hline Carcase & $\begin{array}{c}\text { Radioactivity in } \\
\text { whole carcase } \\
\text { after removal of } \\
\text { Go. }\end{array}$ & $\begin{array}{c}\text { Radioactivity in } \\
\text { whole carcase } \\
\text { after removal of } \\
\text { GI tract and skin (counts/s) }\end{array}$ & $\begin{array}{c}\text { Radioactivity } \\
\text { on skin (\%) }\end{array}$ \\
\hline 1 & 32 & 5 & $84 \cdot 4$ \\
2 & 34 & 6 & $\begin{array}{c}82 \cdot 4 \\
84 \cdot 0\end{array}$ \\
3 & 25 & 4 & Mean $83 \cdot 6$ \\
\hline
\end{tabular}


average weights of material of this radioactive concentration which were present in the piglets during the experiments. These values were calculated by dividing the values of mean whole-body radioactivity in Table 2 by the relevant value of the mean radioactive concentration of faeces and bedding in Table 3. The mean ( $\pm \mathrm{SE}$ ) amount of faeces and bedding present in the piglets was $20.9 \pm 2.5 \mathrm{~g}$ with a range between 5.7 and $86.4 \mathrm{~g}$.

No radioactivity was cietected either in the blood samples taken from the piglets just before slaughter or in the milk samples taken from the sows.

The proportion of the whole-body radioactivity present in the gastrointestinal tract of each piglet was determined by counting each carcase after slaughter and then recounting it after the gastrointestinal tract had been removed. Table 5 gives the mean results of these measurements for each litter. Between 89 and $95.4 \%$ (mean $91.4 \%$ ) of the whole-body radioactivity was present in the gastrointestinal tract.

The distribution of the radioactivity in the carcase after the gastrointestinal tract had been removed was investigated by removing the skin from three carcases and recounting them. The results are given in Table 6 and show that more than $80 \%$ of the residual radioactivity was present on the skin.

\section{DISCUSSION}

The absence of detectable radioactivity in milk samples taken from the sows at intervals throughout the experiments indicates that the radioactivity measured in the piglets was derived from the sows' radioactive faeces. At slaughter approximately $7 \%(83.6 \%$ of $8.6 \%)$ of this whole-body radioactivity was present as external contamination on the skin (Tables 5 and 6) but the remainder was almost entirely present in the gastrointestinal tract of the piglets. The small amount of radioactivity remaining in the carcases from which both the gastrointestinal tract and skin had been removed (Table 6) was probably the result either of contamination of the carcases with gut contents or of small discrepancies between the efficiencies with which the samples of different weights were counted in the whole-body counter.

The values for the average weights of faeces and bedding present in the piglets (Table 4) are therefore probably over-estimates by approximately $7 \%$. These values may be converted into weights of material ingested daily if an assumption is made about the average passage time of the radioactive material through the gastrointestinal tract. If the average passage time were $24 \mathrm{~h}$ the calculated values would indicate the amounts ingested daily; however, if the passage time were less than $24 \mathrm{~h}$, the average amounts ingested daily would be proportionately larger and if the passage time were longer the amounts ingested daily would be smaller. Observations in other experiments in which piglets have been dosed directly with radioactive materials suggest that the average gut passage time is of the order of $24 \mathrm{~h}$ or less. The results $\mathrm{n}$ Table 4 therefore indicate the approximate quantities of faeces and bedding ingested daily by the piglets in these experiments.

It was not possible to separate the faeces, which were highly radioactive, from the bedding, which was initially free of radioactivity, but which would have become contaminated with radioactivity. Radioastivity was not therefore uniformly distributed among the faeces and bedding which was collected daily and counted in the whole-body counter. The average total wet weight of faeces and bedding collected daily was approximately $8.5 \mathrm{~kg}$ (Table 3). Dry wood shavings $(2 \mathrm{~kg}$ ) were spread in the pens daily. These became wetted with urine but it is unlikely that they would have contributed more than $50 \%$ of the total weight collected. Thus the specific radioactivity (counts/s per $\mathrm{g}$ ) of faeces is unlikely to have been more than twice the average radioactivity of the faeces and bedding together, and the average weight of mater al ingested by the piglets is therefore unlikely to have been over-estimated by a facto: of more than two. From observations of the stomach contents 
of the piglets at slaughter it was clear that they ingested wood shavings as well as faeces; for a piglet which ingested wood shavings and faeces in the proportions in which they were present in the pen, the estimates of daily ingestion of faeces and bedding in Table 4 would be correct, but for piglets which ingested either a higher or lower proportion of faeces the estimates would be too high or too low respectively.

The estimates of daily intake of faeces and bedding are very variable but the variations among piglets within a litter are less than the variations among litters. The variations among litters correspond with qualitative estimates of the 'dirtiness' of the sows. For example the highest amounts ingested were by piglets of litter no. 4 whose sow dunged freely throughout her pen and whose udder was frequently coated with faeces. It was noticeable that after she had suckled the piglets her teats were clean. This fact, together with the particularly high intake of radioactivity by the piglets of this 'dirty' sow, suggests that most of the radioactive material was ingested involuntarily when the piglets were suckling. However, some material may also have been ingested when the piglets were 'rooting' in their pens or when they licked and bit each other.

The results of these experiments show that when sows and their piglets were housed in solid-floored pens the piglets ingested considerable quantities of faeces and bedding material. The mean weight ingested was approximately $20 \mathrm{~g} / \mathrm{d}$ with a range from 5 to $85 \mathrm{~g} / \mathrm{d}$. This material may be of nutritional significance because, for example, of the high concentrations of vitamin $B_{12}$ normally present in faeces (J. E. Ford, personal communication). It may also be possible to change the composition of the sow's faeces in order to make it a useful source of dietary Fe or other minerals for the piglet. Thus, if the fresh faeces contained $2 \mathrm{mg} \mathrm{Fe} / \mathrm{g}$ fresh faeces, every piglet in these experiments would have ingested at least $10 \mathrm{mg} \mathrm{Fe} / \mathrm{d}$, sufficient, if it had been absorbed, to protect them from anaemia. Such a concentration of $\mathrm{Fe}$ in the faeces could easily be obtained by feeding the sow a diet containing approximately $2 \mathrm{~g} \mathrm{Fe} / \mathrm{kg}$ dry matter. Her own requirements during lactation are small, so that virtually all this Fe would pass unabsorbed through her gastrointestinal tract into the faeces. Experiments are in progress to test whether it is possible to prevent anaemia in piglets by feeding the sows diets containing $2 \mathrm{~g} \mathrm{Fe}$ as either $\mathrm{FeSO}_{4}$ or $\mathrm{Fe}_{2} \mathrm{O}_{3} / \mathrm{kg}$ dry matter.

The authors thank Mrs M. Price for her help with these experiments.

\section{REFERENCES}

Brady, P. S., Ku, P. K., Ullrey, D. E. \& Miller, E. R. (1978). J. Anim. Sci. 47, 1135.

Braude, R., Chamberlain, A. G., Kotarbinska, M. \& Mitchell, K. G. (1962). Br. J. Nutr. $16,427$.

Sansom, B. F. \& Gleed, P. T. (1981). Proc. Nutr. Soc. 40, 34A.

Sansom, B. F., Taylor, P. J., Wheelock, D. \& Vagg, M. J. (1971). Mineral Studies with Isotopes in Domestic Animals, p. 125. Vienna: International Atomic Energy Agency.

Venn, J. A., McCance, R. A. \& Widdowson, E. M. (1947). J. comp. Path. 57, 314. 